\title{
DKK1-Neutralizing Monoclonal Antibody DKN-01
}

National Cancer Institute

\section{Source}

National Cancer Institute. DKK1-Neutralizing Monoclonal Antibody DKN-01. NCI

Thesaurus. Code C113331.

A humanized monoclonal antibody directed against Wnt antagonist Dickkopf-1 (DKK1) with potential anti-osteolytic activity. DKK1-neutralizing monoclonal antibody DKN-01 binds to and inhibits DKK1, which restores Wnt pathway signaling. Reactivation of the Wnt signaling pathway may result in the differentiation and activation of osteoblasts within the bone matrix and the reversal of tumor-induced osteolytic disease. Elevated levels of circulating DKK1, a potent Wnt signaling pathway antagonist, is associated with a number of neoplastic diseases. 